\title{
Exumação tectônica e reativação de paleolineamentos no Arco de Ponta Grossa: termocronologia por traços de fissão em apatitas
}

\author{
Ana Olivia Barufi Franco-Magalhães ${ }^{1}$, Peter Christian Hackspacher ${ }^{2}$ \& Antonio Roberto Saad ${ }^{3,4}$
}

\begin{abstract}
Resumo A Plataforma Sulamericana na região sudeste brasileira, particularmente na região do Arco de Ponta Grossa, possui inúmeras descontinuidades de diversas naturezas que denotam reativações rúpteis em nível crustal raso, das quais destacam-se diques básicos, falhas e fraturas, originadas e/ou reativadas em diversos pulsos tectônicos que perduraram desde o Cretáceo Superior até o limite Paleógeno - Neógeno, associado a falhamento normal causando basculamento de blocos. Idades de traços de fissão em apatitas (obtidas em amostras coletadas em rochas da bacia do Paraná, diques básicos, embasamento cristalino e rochas alcalinas do Arco de Ponta Grossa) em associação a evidências geológicas, permitiram a reconstrução de uma história de resfriamento a partir de aproximadamente $60 \mathrm{Ma}$, no eixo central do Arco de Ponta Grossa. Movimentos tectônicos transtensionais ocorridos entre o Paleógeno e Neógeno foram os principais responsáveis pela reativação de zonas de cisalhamento pretéritas e consequente formação do segmento sul das bacias que compõem o Rifte Continental do Sudeste Brasileiro, representado na área de estudo pela bacia de Curitiba, grábens de Guaraqueçaba, Sete Barras e Cananéia; e as formações Pariquera-Açu e Alexandra. No limite Paleógeno - Neógeno, a atuação e associação de eventos transtensionais ligados ao rearranjo estrutural da Plataforma Sulamericana deformaram as seções sedimentares das bacias rifte.
\end{abstract}

Palavras-chave: reativação, exumação tectônica, paleógeno, Arco de Ponta Grossa.

\begin{abstract}
Tectonic exhumation and paleolineaments reactivation of the Ponta Grossa Arch: apatite fission-track thermochronology. The South American Platform in southeastern Brazil is characterized by numerous dikes, shear zones, faults and fractures that seem to be reactivated at shallow crust levels, specially between Upper Cretaceous and Paleogene/Neogene, which caused block tilting and normal faulting. Apatite fission-track ages (obtained in samples collected from Paraná Basin, dikes, Precambrian basement and alkaline rocks in Ponta Grossa Arch) in association with geological evidences, allowed the cooling history reconstruction since approximately $60 \mathrm{Ma}$, in the central axis of Ponta Grossa Arch. Transtensional tectonic movements occurred between Paleogene and Neogene were the responsible for the reactivation of ancient shear zones and origin of southern portion of the Brazilian Southeastern Continental Rifts, represented in the study area by $\mathrm{Cu}$ ritiba basin, Guaraqueçaba, Sete Barras and Cananeia Grabens, and Pariquera-Açu and Alexandra formations. In the Paleogene-Neogene limit, trantensional events related to the rearrangement of South American Platform deformed the sedimentary sections in the rift basins.
\end{abstract}

Keywords: reactivation, exhumation, paleogene, Ponta Grossa Arch.

INTRODUÇÃO Estudos realizados na margem continental brasileira e nas áreas oceânicas adjacentes permitiram a definição e associação entre grandes estruturas transversais e bacias interiores e marginais, possibilitando assim correlações entre as áreas oceânicas e o interior continental (Alves 1981, Asmus \& Guazelli 1981). A integração da faixa delimitada na margem continental brasileira e no oceano pelos lineamentos do Rio de Janeiro e Florianópolis (Alves 1981, Asmus \& Guazelli 1981) e, no continente emerso, pelo Arco de Ponta Grossa, configuram-se como os responsáveis pelo melhor entendimento do papel dessas estruturas na origem do Oceano Atlântico-Sul e evolução tectonosedimentar dessa porção do território brasileiro. O desenvolvimento de tais estruturas observadas na região sudeste brasileira, em especial no Arco de Ponta Grossa (Fig. 1), remete ao entendimento dos processos relacionados aos efeitos da separação das placas Sulamericana e Africana, através de pulsos ascensionais da proto-Serra do Mar (Cretáceo Superior - Paleógeno) (Zalán et al. 1990, Chang et al. 1992, Vignol-Lelarge et al. 1994).

O Arco de Ponta Grossa e seus alinhamentos estruturais de direção NW-SE (Guapiara, São Jerônimo-Curiúva, Rio Alonzo e Rio Piqueri) parecem con-

$1^{*}$ - Universidade Estadual Paulista, Depto. de Petrologia e Metalogenia, Programa de Pós-Graduação em Geociências, Rio Claro (SP), Brasil. E-mail: afmagalhaes@prof.ung.br

2 - Universidade Estadual Paulista, Depto. de Petrologia e Metalogenia, Rio Claro (SP), Brasil. E-mail: phack@rc.unesp.br

3 - Universidade Estadual Paulista, Depto. de Geologia Aplicada, Rio Claro (SP), Brasil. E-mail: asaad@prof.ung.br

4 - Centro de Pós-Graduação, Pesquisa e Extensão, Universidade Guarulhos, Guarulhos (SP), Brasil.

"Endereço atual: Centro de Pós-Graduação, Pesquisa e Extensão, Universidade Guarulhos, Guarulhos (SP) 


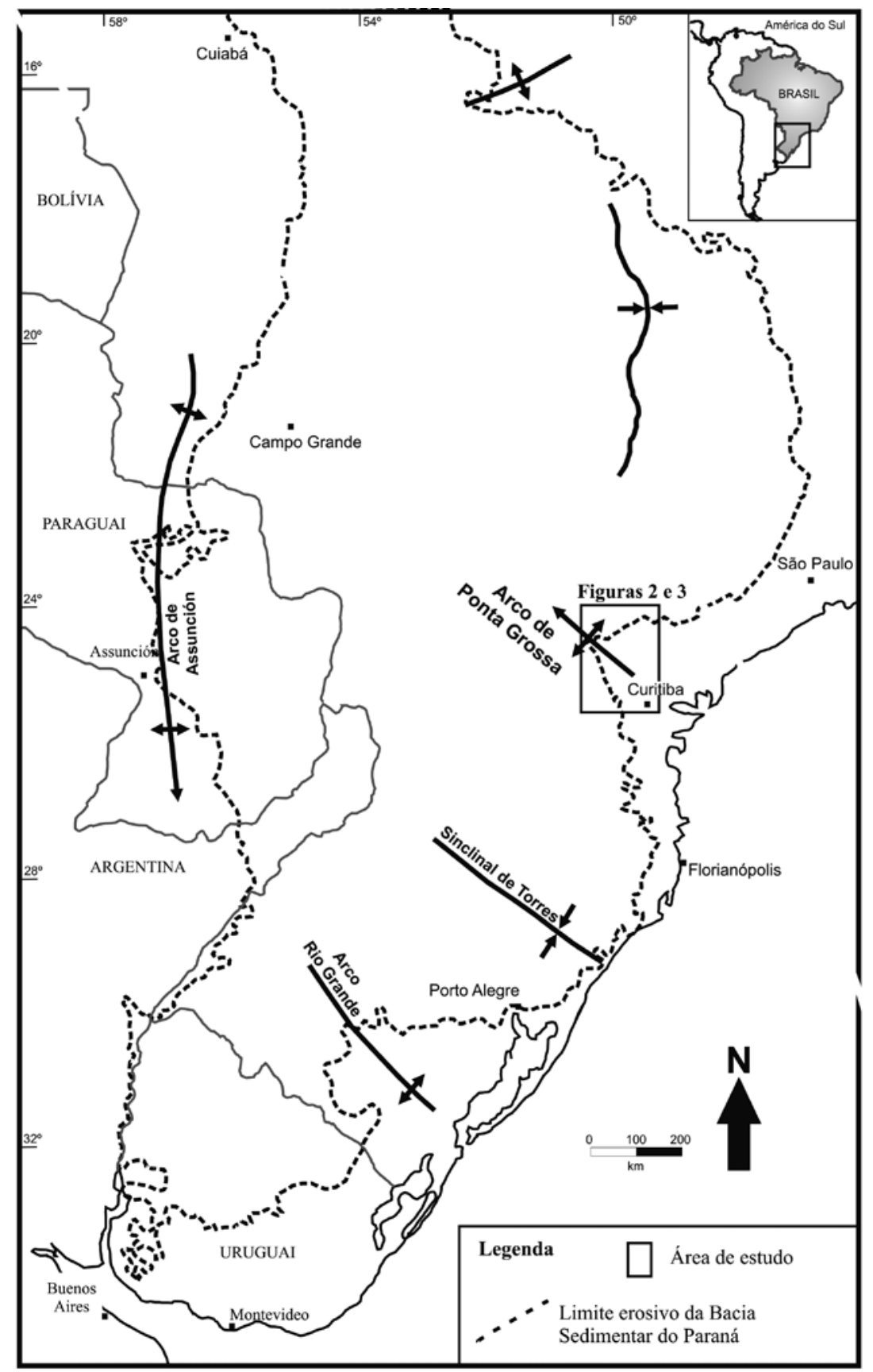

Figura 1 - Localização do Arco de Ponta Grossa, com os principais segmentos estruturais definidos por Zalán et al. (1990).

dicionar muito fortemente a evolução tectônica dessa faixa de estruturação desde o Devoniano, porém com maior acentuação no Carbonífero Superior (Zalán et al. 1990), principalmente durante a Reativação Wealdeniana (Almeida 1969, 1981, 1983, Fulfaro et al. 1982, Ferreira 1982, Zalán et al. 1990). A região pesquisada apresenta-se domeada principalmente à partir do Triássico - Jurássico (Zalán et al. 1987), embora também existam fortes evidências de reativação no Cretáceo Inferior, associado à abertura do Oceano Atlântico-Sul (Almeida et al. 1996, Milani \& Ramos 1998, Franco 2006); no Cretáceo Superior, durante o soerguimento da Serra do Mar (Vignol-Lelarge et al. 1994), e no Pa- leógeno (Tello et al. 2003, Hackspacher et al. 2004). Entretanto, os alinhamentos de direção ENE-WSW, constituídos por antigas falhas e zonas de cisalhamento no embasamento pré-cambriano, foram reativados como falhas normais no Paleógeno (Eoceno-Oligoceno) e deram origem à um corredor de vales tectônicos denominados de Sistema de Riftes Cenozóicos do Sudeste Brasileiro (Zalán \& Oliveira 2005), representado na área de estudo pela bacia de Curitiba (Riccomini 1989).

A análise do relevo da região baseada em Modelo Digital de Elevação do Terreno constituído a partir de imagens SRTM (Fig. 2) evidencia que sua evolu- 


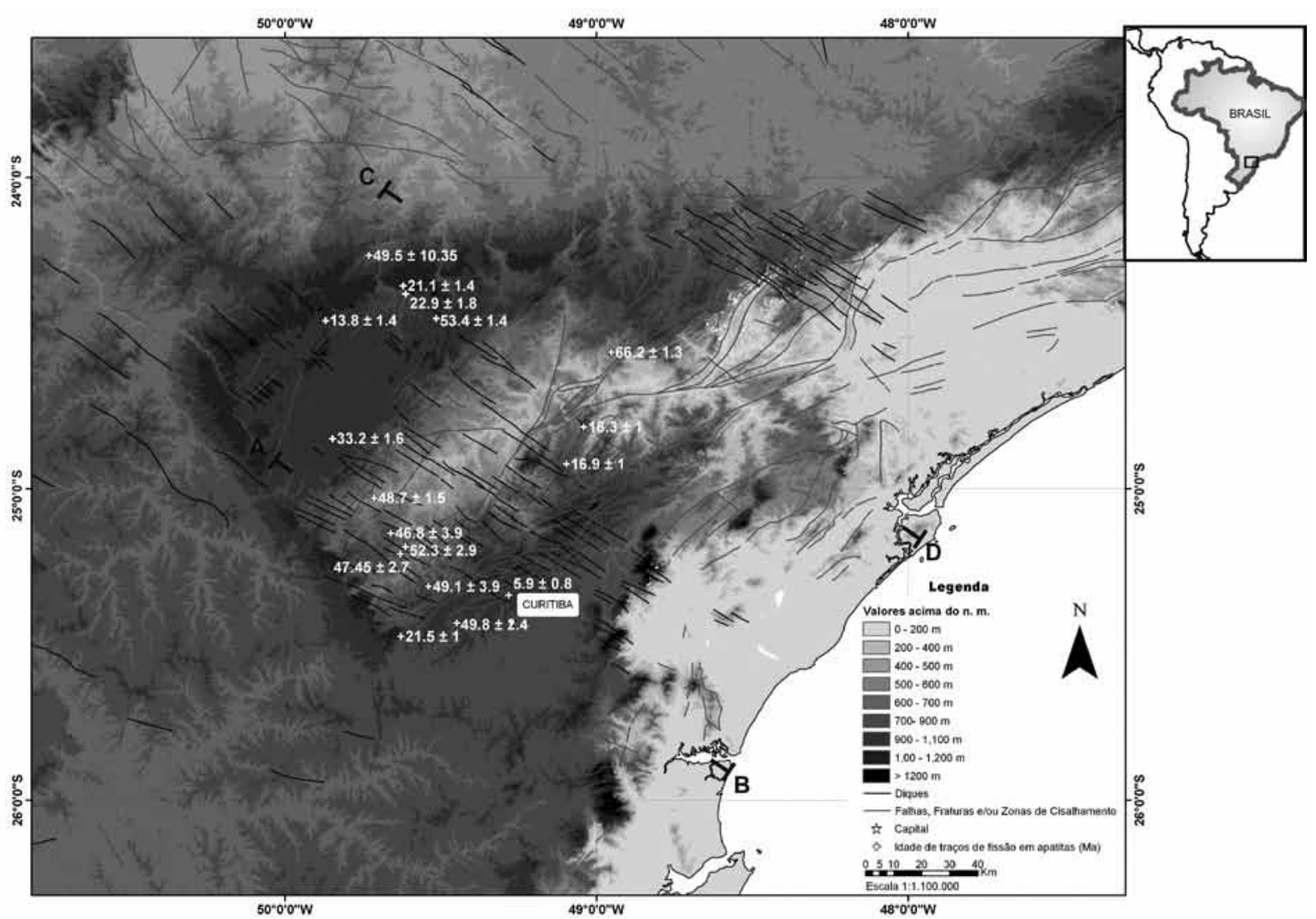

A

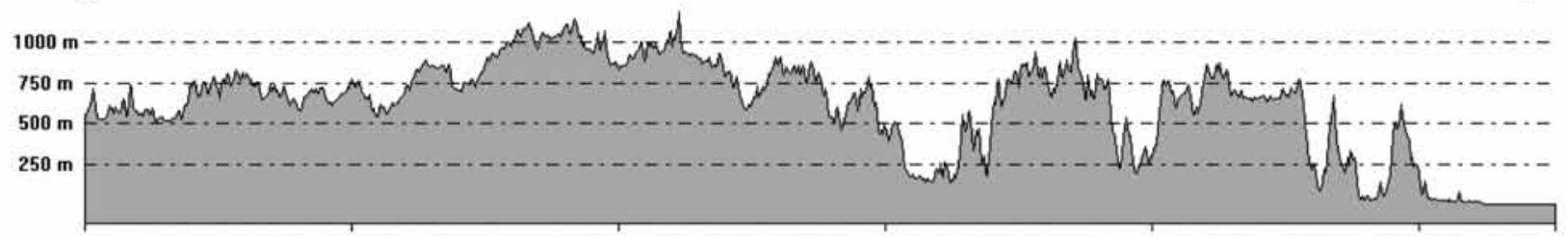

C

D

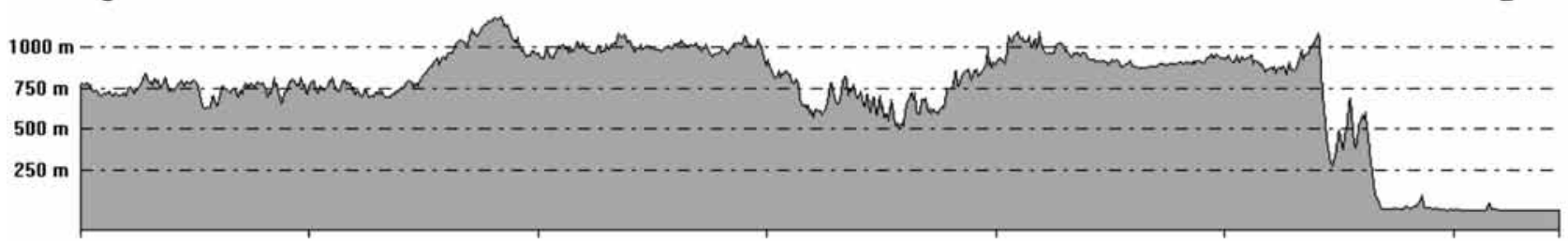

Figura 2 - Modelo Digital de Elevação do Terreno (GTOPO30/USGS 2000) com representação de diques, falhas, pontos amostrados e respectivos perfis topográficos.

ção é provavelmente controlada pelos alinhamentos que compõem o Arco de Ponta Grossa, marcados por diques, fraturas e falhas de direções NW e NE. Além disso, é também observado o truncamento das rochas pré-cambrianas nos sedimentos paleozóicos da bacia do Paraná, e escalonamento do relevo em planaltos como resultado da tectônica paleógena e das erosões química e física nos blocos compartimentados (Melo et al. 2000, Römer 2008).

A termocronologia por traços de fissão (TTF) em apatitas mostra-se como uma ferramenta adequada para a reconstrução dos eventos térmicos, principal- mente aqueles associados a processos de caráter tectônicos e erosivos nas porções superiores da crosta terrestre (no máximo a $5 \mathrm{~km}$ de profundidade, a depender do grau geotérmico) (Wagner \& Van Den Haute 1992, Reiners \& Ehlers, 2005). Esta técnica, portanto, tem sido bastante útil no entendimento dos eventos responsáveis pela estruturação de diferentes setores da Plataforma Sulamericana, em especial a região sudeste brasileira, através do reconhecimento e identificação dos pulsos de soerguimento e erosão associados a alçamentos tectônicos, muitas vezes ocorridos em zonas aquecidas da Plataforma Sulamericana, a partir do Cretáceo (Hacks- 
pacher et al. 2003, 2004, Tello et al. 2003, Franco et al. 2005, Hackspacher et al. 2007). A associação entre eventos termotectônicos, relacionados a reativação de zonas de cisalhamento pré-cambrianas e de falhas, com eventos de soerguimento e de erosão, são importantes para o entendimento da evolução do Arco de Ponta Grossa, principalmente a partir do Cretáceo Inferior.

A presente pesquisa foca em um estudo termocronológico detalhado em traços de fissão em apatitas e apresenta as idades das amostras coletadas no embasamento pré-cambriano adjacente à bacia de Curitiba, e discute a influência da reativação dos alinhamentos na história evolutiva desta região (Fig. 3).

\section{CONSIDERAÇÕES GEOLÓGICAS E GEOMOR-} FOLÓGICAS Localizado na porção sul-sudeste brasileira, o Arco de Ponta Grossa se insere nas províncias geológicas Mantiqueira (Arqueano-Cambriano) e Paraná (Ordoviciano-Cretáceo) (Fig. 3). A Província Mantiqueira (Almeida et al. 1977, 1981) é composta por rochas pré-cambrianas que se estruturam preferencialmente na direção NE-SW, e constituída por inúmeras unidades metassedimentares terrígenas e químicas associadas a metavulcânicas, atravessadas por diversos corpos graníticos (Almeida 1956, Hasui et al. 1975, Campanha et al. 1987, Bergmann 1988, Fiori 1992, Campos Neto 2000).

Após sucessivos episódios colisionais relacio- nados à aglutinação de blocos crustais justapostos por meio de faixas móveis associadas à Orogênese Brasiliana - Pan-Africana (Almeida et al. 2000, Cordani et al. 2000) e sua consolidação durante o Paleozóico, originou-se o Paleocontinente Gondwana. Este, tornouse palco de intenso aporte sedimentar, resultando na acumulação de sucessões sedimentares fanerozóicas ao longo de sua margem e sobre porções de seu interior cratônico. Estas últimas originaram grandes bacias intracratônicas, entre elas a bacia do Paraná (Milani 1997). A inserção e evolução da bacia do Paraná no interior cratônico do Gondwana desde o Ordoviciano possui uma estreita relação com um extenso cinturão fanerozóico marcado pela sucessão dos ciclos orogênicos nos Andes (Milani 1997, Milani \& Ramos 1998). Cada um desses eventos orogênicos possui grande influência temporal nos ciclos de subsidência e sucessivas fases de sedimentação na bacia (Milani 1997). Um extenso evento vulcânico de natureza fissural, denominado de Formação Serra Geral, foi datado de aproximadamente $132 \mathrm{Ma}$ (Renne et al., 1992) e cobriu cerca de $75 \%$ de toda a superfície da Bacia do Paraná (Piccirillo \& Melfi 1988, Piccirillo et al. 1988). Neste mesmo período, soleiras e diques de diabásio, estes últimos denominados de Enxame de Diques do Arco de Ponta Grossa, intrudiram as rochas neopaleozóicas da bacia do Paraná, principalmente aquelas pertencentes

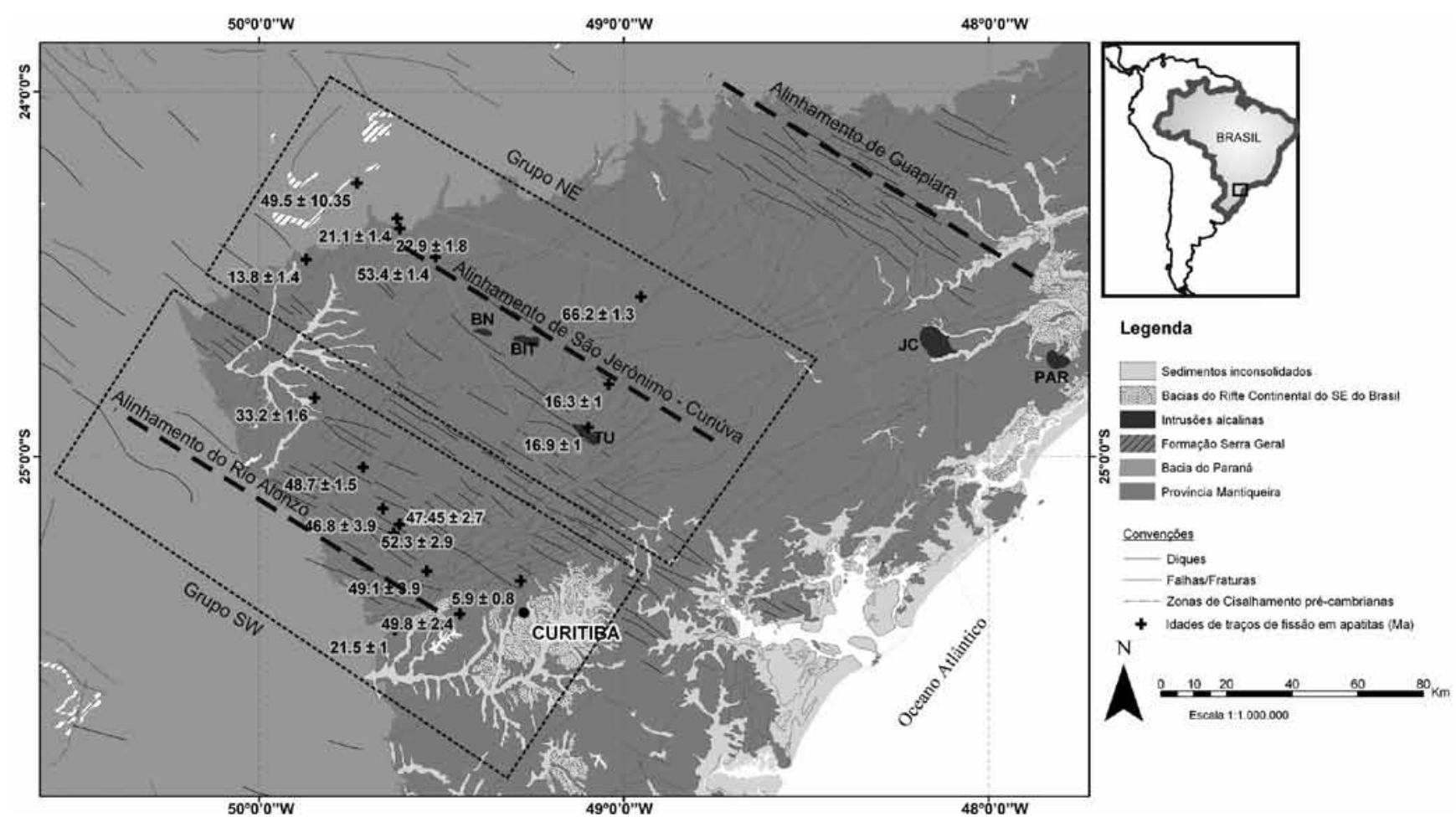

Figura 3 - Mapa geológico da área de estudo com a localização das amostras coletadas, segundo disposição em Grupo $S W$ e Grupo NE, cujos limites são representados por retângulos tracejados. Base geológica de CPRM (Bizzi et al. 2001) e MINEROPAR (2003). Alinhamentos estruturais e magnéticos definidos com base nos trabalhos de Ferreira (1982) e Portela Filho \& Ferreira (2003). PAR - Pariquera - Açu; JC - Jacupiranga; BN - Banhadão; BIT - Barra do Itapirapuã; TU - Tunas. 
às formações Rio Bonito e Irati e, em menor proporção o Grupo Itararé; bem como rochas pertencentes ao seu embasamento cristalino. Este enxame de diques constitui a feição geológica mais notável dos alinhamentos estruturais, de direção preferencial entre N50W e N60W, com extensão que varia de alguns metros a dezenas de quilômetros, datados entre 129 e $131 \mathrm{Ma}$ (Renne et al. 1996). Concomitantemente ao magmatismo básico, segue um período de magmatismo alcalino na região. Inúmeros corpos (plugs, stocks) compõem a denominada Província Alcalina do Arco de Ponta Grossa, totalizando cerca de quinze intrusões simples ou complexos múltiplos (Almeida 1983, Riccomini et al. 2005). De uma maneira geral, caracterizam-se por serem complexos petrograficamente heterogêneos (associações alcalinas, gabróides e ultramáficas), intrudidos em duas fases: uma contemporânea ao magmatismo basáltico (pré-Aptiano) e outra possivelmente associada ao soerguimento tectônico da Serra do Mar, ocorrido entre o Cretáceo o Paleógeno (Almeida 1986). Entre as principais intrusões destacam-se Jacupiranga, Juquiá, Barra do Itapirapuã, Mato Preto, Cananéia, Tunas, dentre outras. (Almeida 1983).

Almeida (1983) observou que as intrusões alcalinas da região do Arco de Ponta Grossa se encontram fora da área de exposição dos diques de diabásio, mas intensamente afetadas pela reativação das fraturas e falhas de direção NW nesta área de estudo. Machado Jr. (2000) afirmou que durante o Cretáceo Inferior essa região esteve envolvida em um sistema tectônico distensivo, com $\sigma_{3}$ orientado a N30-40E, e que gerou abertura para intrusão de complexos alcalinos posicionados no cruzamento de estruturas profundas de direções NW e NE. Tal fato é também corroborado por Riccomini (1995), que sugeriu que a maioria das rochas alcalinas foram intrudidas sob regime de stress extensional, com $\sigma_{3}$ orientado a NE-SW.

No Cretáceo Superior, uma seqüência sedimentar foi depositada sobre a discordância erosiva dos basaltos da Formação Serra Geral (Milani 1997). A "bacia Bauru", como chamada por diversos autores (Fernandes \& Coimbra 1996, Riccomini 1997, Fernandes \& Coimbra 2000), foi originada através de processos de soerguimento da margem continental sudeste brasileira que originou durante o Aptiano e permitiu a formação de uma rede de drenagem que fluísse para o interior continental (Asmus 1981). Segundo Zalán \& Oliveira (2005), à medida que havia o soerguimento, o topo dos remanescentes topográficos era nivelado pela erosão. Dessa forma, como resposta a esse processo no interior do continente, a deposição de diversos litotipos deu-se como conseqüência aos vários pulsos da movimentação tectônica da margem continental. (Fulfaro et al. 1982).

A sedimentação paleógena da área (Melo et al. 1985, Salamuni et al. 2003) é representada pelo segmento ocidental das bacias que compõem o Rifte Continental do Sudeste do Brasil (RCSB), composto pela bacia de Curitiba e a área de ocorrência da Formação Alexandra, os grábens de Guaraqueçaba, Sete Barras e Cananéia, e a área de ocorrência da Formação Pariquera Açu (Riccomini et al. 2004) (Fig. 3). A origem deste sistema de riftes, composto pelas bacias de Curitiba, São Paulo, Taubaté, Resende e Volta Redonda; e compartimentos menores, tais como grábens, subgrábens e hemigrábens, tem sido atribuída por Zalán \& Oliveira (2005) a uma tectônica distensional típica, apresentando blocos falhados rotacionados e grábens (assimétricos ou simétricos) com bordas falhadas e/ou flexuradas. A bacia de Curitiba é delimitada por falhas normais de direção NE na sua borda noroeste, NNE na borda sudeste, e N-S na borda leste (Salamuni 1998). A sucessão sedimentar basal, de natureza rudácea, é proveniente da Serra do Mar e sugere basculamento do assoalho para E e SE (Riccomini et al. 2004). Seus padrões de drenagem são preferencialmente controlados pelos alinhamentos estruturais que seccionam o embasamento. À partir do Pleistoceno, a exposição de blocos tectônicos e, concomitantemente, em clima úmido, originou seu entalhamento através dos processos de erosão e dissecação (Salamuni 1998, Salamuni et al. 2003). Os grábens de Sete Barras e Cananéia constituem uma depressão alongada na direção NE, com espessura máxima de sedimentos entre $200 \mathrm{~m}$ e $500 \mathrm{~m}$, respectivamente (Melo et al. 1989, Souza et al. 1996). Os sedimentos do Gráben de Sete Barras alongam-se para sudeste, em ocorrências descontínuas, controladas por falhas de direção WNW a ENE (Melo 1990), ao longo de uma faixa grosseiramente delimitada pelo enxame de diques eocretáceos que compõem o Alinhamento do Guapiara, e daí para sudoeste, rumo à região da Baía de Paranaguá (Riccomini et al. 2004).

O relevo paranaense é compartimentado sob a forma de escalonamento de planaltos com caimento suave para oeste, divididos em três grandes setores: Primeiro, Segundo e Terceiro Planalto Paranaense (Maack 1948, Melo 1990). A área de estudo localiza-se no Primeiro Planalto Paranaense, caracterizado pelas rochas pré-cambrianas do embasamento cristalino, limitado a leste pela Serra do Mar e a oeste, pela "Escarpa Devoniana". Ab'Saber \& Bigarella (1961) caracterizaram uma superfície de aplainamento do topo e da base do escarpamento, denominada de Superfície Purunã (cuja cota média é de $1.190 \mathrm{~m}$ ), correlacionada à Superfície Sulamericana, reconhecida por King (1956) e correspondente à Superfície Japi, no estado de São Paulo (Almeida 1964). A existência desta superfície sustenta a característica do relevo estratificado, relacionado a diversos pulsos de soerguimento e períodos de denudação intensa, cujos depósitos associados a estas superfícies foram descritos em parte por Bigarella \& Mousinho (1965) próximo a Curitiba e na Serra da Graciosa (PR). Em cotas altimétricas menores, da ordem de $900 \mathrm{~m}$, pode ocorrer um outro compartimento aplainado, provavelmente do OligocenoMioceno (King 1956), embutido nos intervalos rebaixados dos restos da Superfície Sulamericana na região e que pode ser denominado de Superfície Velhas (Almeida 1952). Ela seria passível de correlação com a Superfície de Curitiba, chamada por Bigarella et al. (1965) como Pd1 ou superfície de pediplanização mais recente, e caracterizada como uma superfície aplainada do Primeiro Planalto Parananense resultante da atuação de esforços 
tectônicos associados a processos morfoclimáticos, através da alternância de clima úmido e seco.

\section{MÉTODOS}

Termocronologia por traços de fissão em apatitas A TTF em apatitas consiste na análise dos traços de fissão registrados na apatita, como reflexo da evolução térmica da rocha envolvida em processos fanerozóicos ocorridos a temperaturas entre $120^{\circ} \mathrm{C}$ e $60^{\circ} \mathrm{C}$ (Wagner \& Van Den Haute 1992). Esta faixa de temperatura compreende uma zona de temperatura transicional onde ocorrem acumulação de produtos de decaimento radioativo (neste caso, os traços de fissão) e perda de outros elementos (neste caso, o $\left.{ }^{238} \mathrm{U}\right)$. Chama-se Zona de Retenção Parcial e, de uma maneira geral, encontra-se em equilíbrio e a temperatura constante (Bernet 2009). No caso da apatita, a Zona de Retenção Parcial ocorre entre $60 \pm 10^{\circ} \mathrm{C}$ e $110 \pm 10^{\circ} \mathrm{C}$, de forma que os traços de fissão espontâneos são acumulados e tornam-se estáveis se submetidos a temperaturas abaixo de $100^{\circ} \mathrm{C}$, na escala do tempo geológico (Naeser \& Forbes 1976, Gleadow \& Duddy 1981, Green et al. 1989, Reiners \& Ehlers 2005).

Sabe-se que os traços de fissão são encurtados pela ação combinada de tempo e temperatura, cujo processo chama-se annealing. De acordo com os trabalhos de Green (1988) e Guedes et al. (2004), este fenômeno causa uma redução no comprimento do traço e, consequentemente, uma diminuição da densidade superficial dos traços e também da idade de traço de fissão. Neste trabalho, utilizou-se a equação descrita por Guedes et al. (2004), ajustada para os dados experimentais de Tello (1998). Às amostras, durante irradiação com nêutrons térmicos rápidos, foram acoplados vidros dopados em urânio, conforme métodos descritos por Bigazzi et al. (1995a, b, c, 1999) e Iunes et al. (2002).

A correlação entre idades de traços de fissão e altitude tem sido amplamente utilizada para reconstruir taxas de exumação tectônica em diversos ambientes geotectônicos (Fitzgerald et al. 1995, House et al. 1998, Braun 2002). No Brasil, em especial na região sudeste, Gallagher et al. (1995), Hackspacher et al. (2003) e Franco-Magalhães (2009) utilizaram esta análise para estimar e reconstruir as taxas de exumação tectônica do relevo em diversas áreas geológicas. Segundo Braun (2002, 2005) e Braun et al. (2006) esta análise fornece informações sobre a mudança na taxa de erosão atuante nos processos formadores e modificadores do relevo, através da quantificação dos processos de exumação tectônica e de erosão que atuaram e configuraram a paisagem atual.

Com a finalidade de reconstruir os períodos de exumação tectônica e de reativação dos paleolineamentos do Arco de Ponta Grossa, amostras para TTF em apatitas foram coletadas preferencialmente em trends WNW-ESE, paralelas à faixa de estruturação principal da área de estudo (Fig. 2, Fig. 3, Tab. 1). A dinâmica e história evolutiva desta região, principalmente à partir do Cretáceo Inferior, provável(eis) época(s) de (re?) ativação e relação com os eventos tectônicos de soerguimento das serras do Mar e da Mantiqueira são importantes questões que visam o melhor entendimento da evolução do relevo e da paisagem atual na região estudada.

RESULTADOS E DISCUSSÕES As amostras coletadas para TTF em apatitas agrupam-se em duas tendências abrangendo regiões de características, idades de traços de fissão em apatitas e, consequentemente, evolução diferentes, delimitadas através de dois agrupamentos de idades no eixo central do Arco de Ponta Grossa: o Grupo SW, localizado a NW da bacia de Curitiba; e o Grupo NE, localizado a S do alinhamento de Guapiara, W da intrusão de Jacupiranga e N de Curitiba (Fig. 3). Na figura 4(a) encontram-se plotadas as idades de traços de fissão em apatitas versus a altitude atual correspondente a cada amostra coletada e analisada. De maneira geral, nota-se que há uma ligeira tendência de crescimento da idade de traço de fissão com o aumento da altitude. As amostras do Grupo NE apresentam idades que variam entre $22.9 \pm 1.8 \mathrm{Ma}$ e $13.8 \pm 1.4 \mathrm{Ma}$ (com exceções $66.2 \pm 1.3 \mathrm{Ma}, 53.4 \pm 1.4 \mathrm{Ma}$ e $49.5 \pm 10.35 \mathrm{Ma}$ ), e cotas altimétricas entre $1145 \mathrm{~m}$ e $718 \mathrm{~m}$. Aquelas do Grupo SW, por sua vez, possuem idades entre $52.3 \pm 2.9 \mathrm{Ma}$ e $46.8 \pm 3.9 \mathrm{Ma}$ (com exceções $33.2 \pm 1.6 \mathrm{Ma}, 21.5 \pm 1 \mathrm{Ma}$ e $5.9 \pm 0.8 \mathrm{Ma}$ ), e cotas altimétricas entre $1030 \mathrm{~m}$ e $590 \mathrm{~m}$.

$\mathrm{Na}$ figura 4(b) foi plotada a média do comprimento dos traços confinados versus a idade de traço de fissão em apatitas que, de uma maneira geral, não apresenta tendência marcante. Entretanto, observa-se que as amostras do Grupo SW, que registram idades mais antigas, apresentam comprimento médio (entre $12.1 \pm 0.3 \mathrm{e}$ $11.1 \pm 0.2 \mu \mathrm{m}$ ) maior que as amostras do Grupo NE, com idades mais jovens e comprimento médio ligeiramente menor (entre $11.9 \pm 0.8$ e $10.5 \pm 0.4 \mu \mathrm{m}$ ). Dessa forma, pode-se supor que devido as amostras que forneceram idades mais antigas possuírem maior comprimento médio dos traços confinados, elas foram submetidas à um resfriamento comparativamente mais rápido do que as amostras que forneceram idades mais jovens.

Vários autores (como por exemplo, Almeida 1981, Zalán et al. 1990) sugerem que a evolução do Arco de Ponta Grossa esteja associada aos movimentos ascensionais da Plataforma Sulamericana na região sudeste brasileira, ocorridos principalmente a partir do Cretáceo Superior. Outras manifestações, tais como, soerguimento das serras do Mar e da Mantiqueira, reativações de zonas de cisalhamento pretéritas, manifestações magmáticas de natureza básica e alcalina, e processos denudacionais foram os prováveis responsáveis pela estruturação final desta importante feição.

Tais movimentações positivas iniciaram-se durante a ruptura do paleocontinente Gondwana no Cretáceo Inferior através do domeamento da região e subseqüente abertura do Oceano Atlântico-Sul, que culminou com o magmatismo máfico (presente nas bacias sedimentares ou nas suas bordas, seja em forma de derrames, soleiras ou diques) e alcalino (encontrado principalmente no embasamento cristalino do SE brasileiro, ora identificado nas bordas das bacias sedimentares), ocorridos no Cretáceo Inferior, entre aproximadamente $130 \mathrm{Ma}$ e $110 \mathrm{Ma}$ (ex. Jacupiranga, Tunas, Itapirapuã) (Riccomini et al. 2005). 
Tabela 1 - Descrição das amostras para traços de fissão em apatitas e resumo dos dados de traços de fissão. S.No.: número da amostra, $n$ : número de grãos de apatitas contados, $\rho_{s}=$ densidade de traços espontâneos (x10 $)$ $\left.\mathrm{cm}^{2}\right), N_{s}=$ número de traços espontâneos, $\rho_{i}=$ densidade de traços induzidos $\left(x 10^{5} / \mathrm{cm}^{2}\right), N_{i}=$ número de traços induzidos, $\rho_{d}=$ densidade de traços induzidos $\left(x 10^{5} / \mathrm{cm}^{2}\right)$ contados na mica acoplada ao vidro dopado em U. Ida-

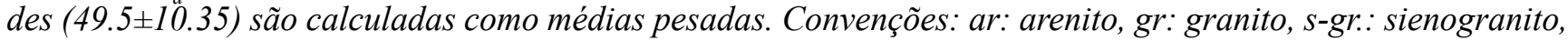
a-gr.: granito alcalino, gn: gnaisse, si.: sienito, db.: diabásio, Neop.: Neoproterozóico, Carb.: Carbonífero, C.I: Cretáceo Inferior. Elevação em metros acima do nível do mar $(\mathrm{m})$.

\begin{tabular}{|c|c|c|c|c|c|c|c|c|c|c|c|c|}
\hline S.-No. & $\begin{array}{l}\text { Elev. } \\
\text { (m) }\end{array}$ & $\begin{array}{l}\text { Idade } \\
\text { Estrat. }\end{array}$ & Coord. & $\begin{array}{l}\mathbf{N}^{0} \text { Irrad. } \\
\text { (vidro U) }\end{array}$ & $\rho_{\mathrm{d}} \pm 1 \sigma$ & $\mathbf{R}_{\mathrm{U}} \times 10^{-9}$ & $\mathbf{n}$ & $\begin{array}{c}\mathbf{U} \\
(\mu \mathrm{g} / \mathrm{g})\end{array}$ & $\begin{array}{c}\rho_{\mathrm{s}} \\
(\mathbf{N s})\end{array}$ & $\begin{array}{c}\rho_{\mathrm{i}} \\
(\mathbf{N i})\end{array}$ & $\begin{array}{l}\text { Idade } \\
\text { (Ma) }\end{array}$ & $\underset{\text { (n) }}{\text { M.T.L. }(\mu \mathrm{m})}$ \\
\hline \multicolumn{13}{|c|}{ Grupo NE (N de Curitiba) } \\
\hline $\begin{array}{l}\text { TF-625 } \\
\text { ar. }\end{array}$ & 1075 & Carb. & $\begin{array}{l}40^{\circ} 44^{\prime} \mathrm{W} \\
24^{\circ} 14^{\prime} \mathrm{S}\end{array}$ & $\begin{array}{l}\text { I180504a } \\
\text { (CN1) }\end{array}$ & $\begin{array}{l}14.06 \\
\pm 0.03\end{array}$ & $\begin{array}{c}9.59 \\
\pm 0.33\end{array}$ & 4 & 14.7 & $\begin{array}{l}5.366 \\
(22)\end{array}$ & $\begin{array}{c}5.122 \\
(21)\end{array}$ & $\begin{array}{c}49.5 \\
\pm 10.35\end{array}$ & - \\
\hline \multirow{2}{*}{$\begin{array}{l}\text { TF-621 } \\
\text { gr. }\end{array}$} & \multirow{2}{*}{1145} & \multirow{2}{*}{ Neop. } & \multirow{2}{*}{$\begin{array}{l}49^{\circ} 37^{\prime} \mathrm{W} \\
24^{\circ} 20^{\prime} \mathrm{S}\end{array}$} & $\begin{array}{c}\text { I051104a } \\
\text { (IRMM) }\end{array}$ & $\begin{array}{c}3.35 \\
\pm 0.05\end{array}$ & $\begin{array}{c}6.63 \\
\pm 0.27\end{array}$ & 15 & \multirow{2}{*}{17.7} & $\begin{array}{l}0.054 \\
(75)\end{array}$ & $\begin{array}{c}0.065 \\
(92)\end{array}$ & \multirow{2}{*}{$\begin{array}{l}21.1 \\
\pm 1.4\end{array}$} & \multirow{2}{*}{$\begin{array}{c}10.9 \pm 0.2 \\
(19)\end{array}$} \\
\hline & & & & $\begin{array}{l}\text { I101204a } \\
\text { (IRMM) }\end{array}$ & $\begin{array}{c}6.51 \\
\pm 0.23\end{array}$ & $\begin{array}{c}4.44 \\
\pm 0.21\end{array}$ & 16 & & $\begin{array}{l}5.42 \\
(77)\end{array}$ & $\begin{array}{l}6.24 \\
(93)\end{array}$ & & \\
\hline \multirow{2}{*}{$\begin{array}{c}\text { TF-620 } \\
\text { db. }\end{array}$} & \multirow{2}{*}{1027} & \multirow{2}{*}{ C.I. } & \multirow{2}{*}{$\begin{array}{l}49^{\circ} 37^{\prime} \mathrm{W} \\
24^{\circ} 22^{\prime} \mathrm{S}\end{array}$} & $\begin{array}{l}\mathrm{I} 180504 \mathrm{~b} \\
\text { (CN2) }\end{array}$ & $\begin{array}{c}4.41 \\
\pm 0.44\end{array}$ & $\begin{array}{l}10.58 \\
\pm 0.25\end{array}$ & 3 & \multirow{2}{*}{22} & $\begin{array}{l}6.52 \\
(24)\end{array}$ & $\begin{array}{l}10.48 \\
(39)\end{array}$ & \multirow{2}{*}{$\begin{array}{r}22.9 \\
\pm 1.8\end{array}$} & \multirow{2}{*}{$\begin{array}{l}11.9 \pm 0.8 \\
\text { (3) }\end{array}$} \\
\hline & & & & $\begin{array}{c}\text { I101204a } \\
\text { (IRMM) }\end{array}$ & $\begin{array}{c}6.51 \\
\pm 0.23\end{array}$ & $\begin{array}{c}4.44 \\
\pm 0.21\end{array}$ & 5 & & $\begin{array}{l}1.87 \\
(44)\end{array}$ & $\begin{array}{l}1.68 \\
(38)\end{array}$ & & \\
\hline $\begin{array}{l}\text { TF-619 } \\
\text { gr. }\end{array}$ & 1048 & Neop. & $\begin{array}{l}49^{\circ} 31^{\prime} \mathrm{W} \\
24^{\circ} 26^{\prime} \mathrm{S}\end{array}$ & $\begin{array}{l}\mathrm{I} 180504 \mathrm{~b} \\
\text { (CN5) }\end{array}$ & $\begin{array}{c}4.41 \\
\pm 0.44\end{array}$ & $\begin{array}{l}10.58 \\
\pm 0.25\end{array}$ & 42 & 9.4 & $\begin{array}{c}3.22 \\
(499)\end{array}$ & $\begin{array}{l}3.51 \\
(555\end{array}$ & $\begin{array}{c}53.4 \\
\pm 1.4\end{array}$ & $\begin{array}{c}11.4 \pm 0.4 \\
(17)\end{array}$ \\
\hline $\begin{array}{l}\text { TF-1007 } \\
\text { gr. }\end{array}$ & 718 & Neop. & $\begin{array}{l}48^{\circ} 58^{\prime} \mathrm{W} \\
24^{\circ} 33^{\prime} \mathrm{S}\end{array}$ & $\begin{array}{l}\text { I160307 } \\
\text { (IRMM) }\end{array}$ & $\begin{array}{c}5.33 \\
\pm 0.52\end{array}$ & $\begin{array}{c}9.95 \\
\pm 0.39\end{array}$ & 79 & 13.1 & $\begin{array}{c}5.28 \\
(1258)\end{array}$ & $\begin{array}{l}3.19 \\
(818\end{array}$ & $\begin{array}{c}66.2 \\
\pm 1.3\end{array}$ & $\begin{array}{c}10.5 \pm 0.4 \\
(38)\end{array}$ \\
\hline $\begin{array}{l}\text { TF-934 } \\
\text { s-gr. }\end{array}$ & 890 & Neop. & $\begin{array}{l}49^{\circ} 02^{\prime} \mathrm{W} \\
24^{\circ} 47^{\prime} \mathrm{S}\end{array}$ & $\begin{array}{l}\text { I221106a } \\
\text { (IRMM) }\end{array}$ & $\begin{array}{c}3.74 \\
\pm 0.53\end{array}$ & $\begin{array}{c}6.98 \\
\pm 0.28\end{array}$ & 28 & 40.4 & $\begin{array}{c}5.8 \\
(161)\end{array}$ & $\begin{array}{l}9.91 \\
(199\end{array}$ & $\begin{array}{l}16.3 \\
\pm 1\end{array}$ & $\begin{array}{c}11.3 \pm 0.3 \\
(19)\end{array}$ \\
\hline $\begin{array}{l}\text { TF-933 } \\
\text { si. }\end{array}$ & 903 & C.I. & $\begin{array}{c}49^{\circ} 05^{\prime} \mathrm{W} \\
24^{\circ} 55^{\prime} \mathrm{S}\end{array}$ & $\begin{array}{l}\text { I221106a } \\
\text { (IRMM) }\end{array}$ & $\begin{array}{c}3.74 \\
\pm 0.53\end{array}$ & $\begin{array}{c}6.98 \\
\pm 0.28\end{array}$ & 40 & 43.2 & $\begin{array}{c}4.59 \\
(155)\end{array}$ & $\begin{array}{l}10.6 \\
(370\end{array}$ & $\begin{array}{l}16.9 \\
\pm 1\end{array}$ & $\begin{array}{c}11.0 \pm 0.6 \\
\text { (3) }\end{array}$ \\
\hline $\begin{array}{l}\text { TF-785 } \\
\text { gr. }\end{array}$ & 1075 & Neop. & $\begin{array}{l}49^{\circ} 52^{\prime} \mathrm{W} \\
24^{\circ} 27^{\prime} \mathrm{S}\end{array}$ & $\begin{array}{l}\text { I130905a } \\
\text { (CN1) }\end{array}$ & $\begin{array}{l}9.80 \\
\pm 0.10\end{array}$ & $\begin{array}{c}6.68 \\
\pm 0.21\end{array}$ & 10 & 0.14 & $\begin{array}{c}19.11 \\
(84)\end{array}$ & $\begin{array}{l}22.91 \\
(100)\end{array}$ & $\begin{array}{c}13.8 \\
\pm 1.4\end{array}$ & $\begin{array}{c}11.1 \pm 0.3 \\
(11)\end{array}$ \\
\hline \multicolumn{13}{|c|}{ Grupo SW (Curitiba e NW) } \\
\hline $\begin{array}{l}\text { TF-1073 } \\
\text { gr. }\end{array}$ & 1008 & Neop. & $\begin{array}{c}49^{\circ} 53^{\prime} \mathrm{W} \\
24^{\circ} 50^{\prime} \mathrm{S}\end{array}$ & $\begin{array}{l}\mathrm{I} 280408 \\
\text { (CN5) }\end{array}$ & $\begin{array}{c}4.99 \\
\pm 0.044\end{array}$ & $\begin{array}{l}11.98 \\
\pm 0.37\end{array}$ & 63 & 30.5 & $\begin{array}{c}6.19 \\
(296)\end{array}$ & $\begin{array}{l}10.27 \\
(500)\end{array}$ & $\begin{array}{c}33.2 \\
\pm 1.6\end{array}$ & $\begin{array}{c}11.4 \pm 0.3 \\
(15)\end{array}$ \\
\hline $\begin{array}{l}\text { TF-1072 } \\
\text { gr. }\end{array}$ & 590 & Neop. & $\begin{array}{l}49^{\circ} 43^{\prime} \mathrm{W} \\
25^{\circ} 01^{\prime} \mathrm{S}\end{array}$ & $\begin{array}{c}\text { I280408 } \\
\text { (CN5) }\end{array}$ & $\begin{array}{c}4.99 \\
\pm 0.04\end{array}$ & $\begin{array}{l}11.98 \\
\pm 0.37\end{array}$ & 54 & 38.7 & $\begin{array}{l}12.02 \\
(439)\end{array}$ & $\begin{array}{l}16.56 \\
(612)\end{array}$ & $\begin{array}{l}48.7 \\
\pm 1.5\end{array}$ & $\begin{array}{c}11.9 \pm 0.2 \\
(26)\end{array}$ \\
\hline $\begin{array}{l}\text { TF-1070 } \\
\text { gr. }\end{array}$ & 871 & Neop. & $\begin{array}{l}49^{\circ} 40^{\prime} \mathrm{W} \\
25^{\circ} 08^{\prime} \mathrm{S}\end{array}$ & $\begin{array}{c}\text { I280408 } \\
\text { (CN5) }\end{array}$ & $\begin{array}{c}4.99 \\
\pm 0.04\end{array}$ & $\begin{array}{l}11.98 \\
\pm 0.37\end{array}$ & 27 & 16 & $\begin{array}{c}5.97 \\
(116)\end{array}$ & $\begin{array}{l}6.72 \\
(144)\end{array}$ & $\begin{array}{l}46.8 \\
\pm 3.9\end{array}$ & $\begin{array}{c}11.7 \pm 0.3 \\
(32)\end{array}$ \\
\hline $\begin{array}{c}\text { TF-1069 } \\
\text { gr. }\end{array}$ & 670 & Neop. & $\begin{array}{c}49^{\circ} 37^{\prime} \mathrm{W} \\
25^{\circ} 11^{\prime} \mathrm{S}\end{array}$ & $\begin{array}{c}\mathrm{I} 280408 \\
\text { (CN5) }\end{array}$ & $\begin{array}{l}4.99 \\
\pm 0.04\end{array}$ & $\begin{array}{l}11.98 \\
\pm 0.37\end{array}$ & 51 & 14.7 & $\begin{array}{c}6.01 \\
(277)\end{array}$ & $\begin{array}{c}6.29 \\
(294)\end{array}$ & $\begin{array}{l}52.3 \\
\pm 2.9\end{array}$ & $\begin{array}{c}11.5 \pm 0.3 \\
(17)\end{array}$ \\
\hline $\begin{array}{c}\text { TF-1068 } \\
\text { a- gr. }\end{array}$ & 845 & Neop. & $\begin{array}{l}49^{\circ} 38^{\prime} \mathrm{W} \\
25^{\circ} 12^{\prime} \mathrm{S}\end{array}$ & $\begin{array}{l}\mathrm{I} 280408 \\
\text { (CN5) }\end{array}$ & $\begin{array}{c}4.99 \\
\pm 0.04\end{array}$ & $\begin{array}{l}11.98 \\
\pm 0.37\end{array}$ & 37 & 12.6 & $\begin{array}{l}4.41 \\
(203)\end{array}$ & $\begin{array}{c}5.37 \\
(262)\end{array}$ & $\begin{array}{l}47.45 \\
\pm 2.7\end{array}$ & $\begin{array}{c}12.1 \pm 0.3 \\
\text { (11) }\end{array}$ \\
\hline $\begin{array}{l}\text { TF-1065 } \\
\text { gr. }\end{array}$ & 812 & Neop. & $\begin{array}{l}49^{\circ} 43^{\prime} \mathrm{W} \\
25^{\circ} 01^{\prime} \mathrm{S}\end{array}$ & $\begin{array}{c}\mathrm{I} 280408 \\
\text { (CN5) }\end{array}$ & $\begin{array}{l}4.99 \\
\pm 0.04\end{array}$ & $\begin{array}{l}11.98 \\
\pm 0.37\end{array}$ & 38 & 18.7 & $\begin{array}{c}6.22 \\
(139)\end{array}$ & $\begin{array}{l}8.18 \\
(182)\end{array}$ & $\begin{array}{l}49.1 \\
\pm 3.9\end{array}$ & $\begin{array}{c}11.5 \pm 0.2 \\
(34)\end{array}$ \\
\hline $\begin{array}{l}\text { TF-1061 } \\
\text { gr. }\end{array}$ & 924 & Neop. & $\begin{array}{l}49^{\circ} 26^{\prime} \mathrm{W} \\
25^{\circ} 25^{\prime} \mathrm{S}\end{array}$ & $\begin{array}{c}\text { I280408 } \\
\text { (CN5) }\end{array}$ & $\begin{array}{c}4.99 \\
\pm 0.04\end{array}$ & $\begin{array}{l}11.98 \\
\pm 0.37\end{array}$ & 25 & 68.2 & $\begin{array}{l}23.3 \\
(220)\end{array}$ & $\begin{array}{l}28.7 \\
(270)\end{array}$ & $\begin{array}{l}49.8 \\
\pm 2.4\end{array}$ & $\begin{array}{c}12.1 \pm 0.2 \\
(23)\end{array}$ \\
\hline $\begin{array}{l}\text { TF-929 } \\
\text { gr. }\end{array}$ & 1030 & Neop. & $\begin{array}{l}49^{\circ} 37^{\prime} \mathrm{W} \\
25^{\circ} 27^{\prime} \mathrm{S}\end{array}$ & $\begin{array}{l}\text { I221106a } \\
\text { (IRMM) }\end{array}$ & $\begin{array}{c}3.74 \\
\pm 0.53\end{array}$ & $\begin{array}{c}6.98 \\
\pm 0.28\end{array}$ & 77 & 25.4 & $\begin{array}{c}4.11 \\
(343)\end{array}$ & $\begin{array}{c}6.22 \\
(533)\end{array}$ & $\begin{array}{c}21.5 \\
\pm 1\end{array}$ & $\begin{array}{c}11.1 \pm 0.2 \\
(44)\end{array}$ \\
\hline $\begin{array}{l}\text { TF } 930 \\
\text { gn. }\end{array}$ & 920 & Neop. & $\begin{array}{l}49^{\circ} 17^{\prime} \mathrm{W} \\
25^{\circ} 19^{\prime} \mathrm{S}\end{array}$ & $\begin{array}{l}\text { I221106a } \\
\text { (IRMM) }\end{array}$ & $\begin{array}{c}3.74 \\
\pm 0.53\end{array}$ & $\begin{array}{c}6.98 \\
\pm 0.28\end{array}$ & 3 & 47.5 & $\begin{array}{c}20.24 \\
(17)\end{array}$ & $\begin{array}{c}116.45 \\
(107)\end{array}$ & $\begin{array}{c}5.9 \\
\pm 0.8\end{array}$ & $\begin{array}{l}11.4 \pm 0.3 \\
\text { (3) }\end{array}$ \\
\hline
\end{tabular}



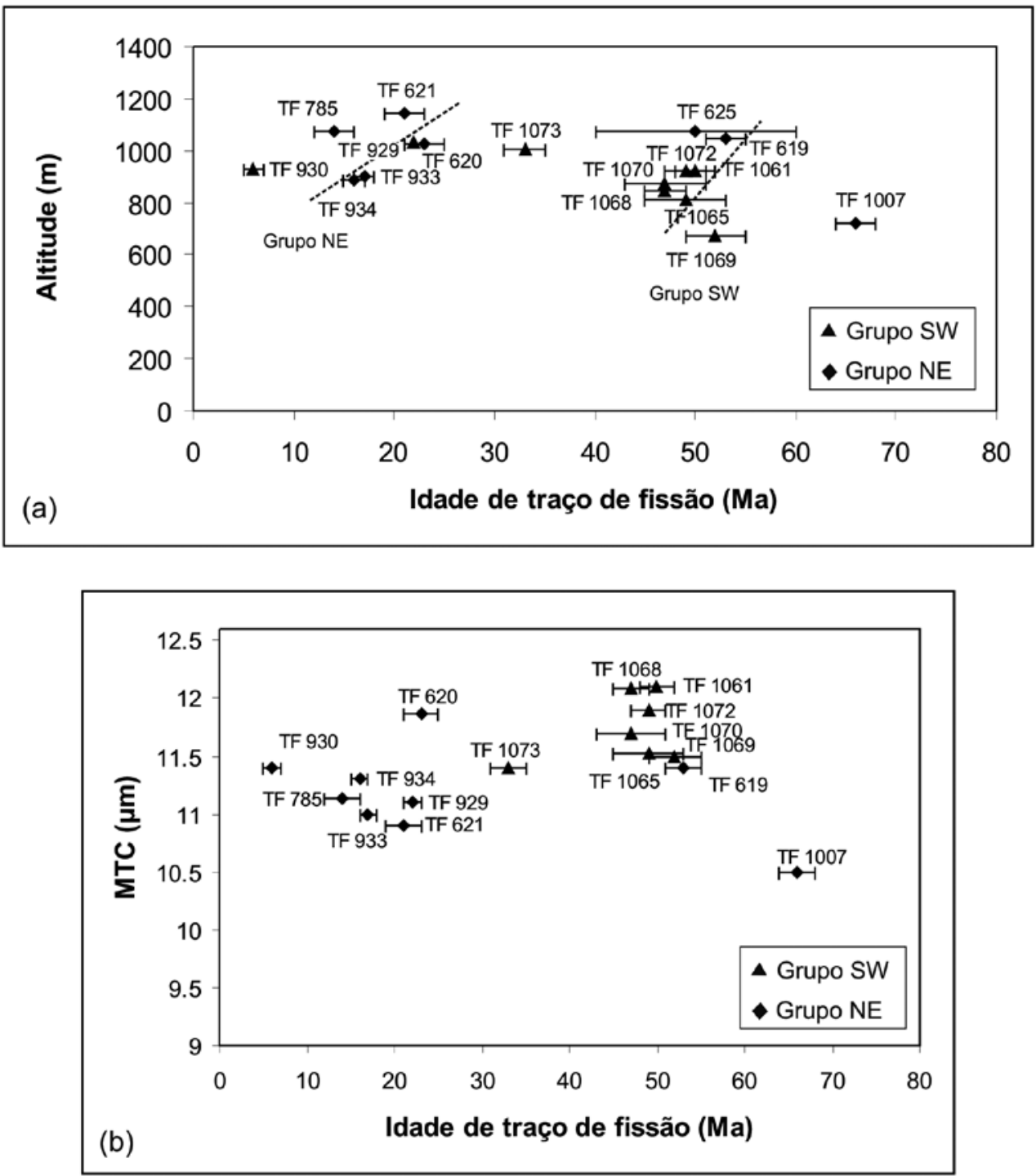

${ }^{*}$ TF 625 não possui valor de MTC

Figura 4 - (a) Idade de traços de fissão em apatita (Ma) x Altitude (m). (b) Idade de traço de fissão em apatita (Ma) x média normal dos traços confinados (MTC) $(\mu \mathrm{m})$. Ver texto para discussão.

As idades de traços de fissão em apatitas obtidas no Arco de Ponta Grossa, em associação a evidências geológicas e geomorfológicas, permitem a reconstrução desta feição principalmente a partir de aproximadamente $66 \mathrm{Ma}$ (Maastrichiano), mas com grande ênfase entre 25-15 Ma, mais especificamente entre o Oligoceno e Mioceno.

Através do gráfico de idades de traços de fissão em apatitas versus a altitude atual (Fig. 4a) foi possível estimar uma taxa de exumação tectônica para cada uma das áreas referentes aos Grupos NE e SW, e portanto, refletem uma estimativa para as respectivas regiões onde as amostras foram coletadas. Esta taxa considera o erro de idade de traços de fissão em apatitas associado a cada uma das amostras, em função da altitude atual. O Grupo SW, que possui idades mais antigas, apresenta taxa de exumação tectônica de $\sim 41 \mathrm{~m} / \mathrm{Ma}$; enquanto o
Grupo NE, que apresenta idades mais jovens, tem uma taxa de exumação tectônica de $\sim 20 \mathrm{~m} / \mathrm{Ma}$.

As idades obtidas marcam importantes episódios de soerguimento e exumação tectônica no eixo central do Arco de Ponta Grossa. O evento ocorrido em torno de $66 \mathrm{Ma}$ está relacionado ao alçamento do embasamento cristalino, como reflexo do soerguimento e exumação tectônica de regiões que serviram como áreas-fonte para a bacia de Santos nesta época. Pereira \& Feijó (1994) e Modica \& Brush (2004) reconheceram uma discordância regional na bacia de Santos em aproximadamente $70 \mathrm{Ma}$, sugerindo uma associação com um possível alçamento do embasamento cristalino adjacente à essa bacia entre o Maastrichiano e Paleoceno Inferior. O mesmo evento foi também reconhecido por Tello et al. (2003) nas serras do Mar e da Mantiqueira no estado de São Paulo, interpretado 
como possível reativação das zonas de cisalhamento pré-cambrianas. Pereira \& Feijó (1994) e Zalán \& Oliveira (2005) afirmaram que no Cretáceo Superior, entre aproximadamente 90 e $65 \mathrm{Ma}$, a bacia de Santos sofrera grande aporte de material sedimentar clástico e que assim constituíram grandes receptores do material erodido das áreas-fonte adjacentes, podendo refletir a formação da Superfície Sulamericana (King 1956) também na área de estudo, que foi bastante atuante em toda a região sudeste brasileira entre o Cretáceo Superior - Paleógeno (Almeida \& Carneiro 1998).

As idades registradas do final do Paleógeno e início do Neógeno (entre 25Ma e $15 \mathrm{Ma}$ ) são associadas aos fenômenos tectônicos que controlaram os ciclos deposicionais das bacias que compõem o Rifte Continental do Sudeste Brasileiro, e que estão representadas na área de estudo principalmente pela bacia de Curitiba (Salamuni 1998), pela Formação PariqueraAçu; e os grábens de Guaraqueçaba, Cananéia e Sete Barras (Melo et al. 1985, Riccomini 1989, Salamuni et al. 2003). Essas bacias foram originadas através da reativação de zonas de cisalhamento neoproterozóicas, reativadas como falhas normais, de direção preferencial NE (Riccomini 1989). No início da evolução da bacia de Curitiba, no Oligoceno-Mioceno, a tectônica presente na época foi a responsável pelo controle da sedimentação na bacia. Entretanto, evidências na arquitetura estratigráfica e na distribuição faciológica sugerem que os ciclos deposicionais desta bacia estiveram ligados às atividades tectônicas cíclicas de suas falhas controladoras (Salamuni 1998).

CONCLUSÕES Com base no diagrama idade de traços de fissão x altitude (Fig. 4a) estima-se que a taxa de exumação tectônica do Grupo SW é relativamente bem maior que aquela calculada para o Grupo NE. Isso significa que, embora a região abrangida pelo Grupo SW tenha apresentado idades mais antigas, o pacote exumado nesta porção é bem maior que o outro. Além disso, vale ressaltar que a transecta de amostras coletadas no Grupo SW localiza-se na direção NW da bacia de Curitiba, cruzando diversas zonas de cisalhamento précambrianas que foram reativadas como falhas normais no Cretáceo Superior e Paleógeno. Estas zonas de cisalhamento, ao serem reativadas, podem comportar-se como "canais de denudação" que resultam num maior volume de remoção do material. A este fenômeno, Burbank \& Anderson (2001) definiram como Denudação Tectônica, de forma que esta área pode ter se comporta- do, entre o Oligoceno e Mioceno, como área-fonte para a sedimentação neógena na região.

Por outro lado, as amostras localizadas no Grupo NE apresentam idades mais jovens, em uma região que apresenta enxame de diques e intrusões alcalinas entre os afloramentos do pré-cambriano e as rochas da bacia do Paraná. A presença de rochas de natureza alcalina e um número mais expressivo de diques de diabásio podem, de certa forma, influenciar não somente o padrão das idades de traços de fissão, mas sobretudo a história evolutiva e morfológica do relevo, devido a características erosivas inerentes a estes tipos litológicos.

A atuação e associação de regimes de esforços relacionados à tectônica sinistral E-W estão ligadas ao rearranjo estrutural da Plataforma Sulamericana entre o Paleógeno e Neógeno são também responsáveis pela deformação das seções sedimentares que compõem as bacias tafrogências (Salamuni et al. 2003, 2004, Riccomini et al. 2004) e seu reflexo no embasamento cristalino pré-cambriano.

As idades de traços de fissão em apatitas obtidas na região mostraram que o Arco de Ponta Grossa apresenta uma evolução recente, destacando-se dois importantes períodos: o limite Cretáceo Superior Paleógeno, e o limite Paleógeno - Neógeno. A feição positiva do relevo, formada por um levantamento epirogenético de toda a região, juntamente com o paleoclima atuante na época (árido com alternância de chuvas torrenciais) (Salamuni 1998) promoveram a geração de regolitos e modelaram o relevo da região. Além disso, o arqueamento do Arco de Ponta Grossa também influenciou para a aceleração da dissecação e exposição do embasamento. A mudança na morfologia do relevo, entre o Pleistoceno e Holoceno, começou a adquirir o modelado atual da paisagem. Entretanto, a recorrência de processos tectônicos é ainda atuante através de evidências de basculamento e rotação de blocos e mudanças no nível de base das drenagens, através de um possível ajuste tectônico de falhamentos recentes (Römer 2008). Aparentemente, as diferenças entre a morfologia e topografia do relevo em função da alternância do nível de base regional, o controle estrutural e até a distância em relação ao nível do mar parecem contribuir para as diferenças na resposta das escarpas e drenagens às mudanças climáticas do Quaternário.

Agradecimentos Ao suporte financeiro da FAPESP para as atividades de campo (Processo 00/03960-5) e bolsa de Doutorado de A.O.B.F.M. (Processo 05/58704-7).

\section{Referências}

Ab’Saber A.N. \& Bigarella J.J. 1961. Superfícies aplainadas do Primeiro Planalto do Paraná. Boletim Paranaense de Geografia, 4/5:116-125.

Almeida F.F.M. 1952. Novas ocorrências de camadas supostas pliocênicas nos Estados de São Paulo e Paraná. Boletim da Sociedade Brasileira de Geologia, 1(1):53-58.

Almeida F.F.M. 1956. Novas ocorrências de fósseis no Pré-cam- briano brasileiro. Anais da Academia Brasileira de Ciências, 28:54-55.

Almeida F.F.M. 1964. Fundamentos geológicos do relevo paulista. Boletim do Instituto Geográfico e Geológico, IGG, São Paulo, 41:169-263

Almeida F.M.M. 1969. Diferenciação tectônica da Plataforma Brasileira. In: SBG, Congresso Brasileiro de Geologia, 23, 
Salvador, Anais, 29-46.

Almeida F.F.M. 1981. Síntese sobre a tectônica da Bacia do Paraná. In: SBG, Simpósio Regional de Geologia, 3, Curitiba, Atas,1:1-20.

Almeida F.F.M. 1983. Relações Tectônicas das rochas alcalinas mesozóicas da região meridional da Plataforma Sul-Americana. Revista Brasileira de Geociências, 13(3):139-158.

Almeida F.F.M. 1986. Distribuição regional e relações tectônicas do magmatismo pós-paleozóico no Brasil. Revista Brasileira de Geociências, 16(4):325-349.

Almeida F.F.M., Brito Neves B.B., Carneiro C.D.R. 2000. The origin and evolution of the south American Platform. Earth Science Reviews, 50:77-111.

Almeida F.F.M. \& Carneiro C.D.R. 1998. Origem e evolução da Serra do Mar. Revista Brasileira de Geociências, 28(2):135150.

Almeida F.F.M., Carneiro C.D.R., Misuzaki A.M.P. 1996. Correlação do magmatismo das bacias da margem continental brasileira com o das áreas emersas adjacentes. Revista Brasileira de Geociências. (26):125-138.

Almeida F.F.M., Hasui Y., Brito Neves B.B., Fuck R.A. 1977. As províncias estruturais brasileiras. In: SBG, Simpósio de Geologia do Nordeste, 8, Campina Grande, 1977. Atas, p. 363-391.

Almeida F.F.M., Hasui Y., Ponçano W.L., Dantas A.S.L., Carneiro C.D.R., Melo M.S., Bistrichi C.A. 1981. Mapa Geológico do Estado de São Paulo, escala 1:500.000, Nota Explicativa. São Paulo, IPT, Monografias 6, v. 1, 126 p. (Publ. 184).

Alves E.C. 1981. Geologia da margem continental sudeste/sul brasileira e das áreas continentais emersas e oceânicas adjacentes. In: Asmus H.E. (ed.) Estruturas e tectonismo da margem continental brasileira e suas implicações nos processos sedimentares e avaliação do potencial de recursos minerais. Série Projeto REMAC, PETROBRAS/DNPMCPRM/DHN/CNPq, nº 9, p. 145-170.

Asmus H.E. 1981. Relacionamento genético de feições geológicas da margem continental brasileira e da área continental emersa adjacente. In: SBG, Simpósio Regional de Geologia, 3, Curitiba, Atas, 1:262-273.

Asmus H.E. \& Guazelli W. 1981. Sumário das estruturas da margem continental brasileira e das áreas continentais e oceânicas adjacentes. Hipóteses sobre o tectonismo causativo e implicações no prognóstico de seu potencial em recursos minerais. In: Asmus H.E. (ed.) Estruturas e tectonismo da margem continental brasileira e suas implicações nos processos sedimentares e avaliação do potencial de recursos minerais. Série Projeto REMAC, PETROBRAS/DNPM-CPRM/ DHN/CNPq, Série Projeto REMAC nº 9, p. 187-269.

Bergmann M. 1988. Caracterização estratigráfica e estrutural da seqüencia vulcano - sedimentar do Grupo São Roque na região de Pirapora do Bom Jesus, Estado de São Paulo. São Paulo, Dissertação de Mestrado, Instituto de Geociências, Universidade de São Paulo, 155 p.

Bernet M. 2009. A field-based estimate of the zircon fission-track closure temperature. Chemical Geology, 259:181-189.

Bigarella J.J. \& Mousinho M.R. 1965. Significado Paleogeográfico e Paleoclimático dos depósitos Rudáceos. Boletim Paranaense de Geografia, 16-17:7-16.

Bigarella J.J., Mousinho M.R., Silva J.X. 1965. Pediplanos, pedimentos e seus depósitos correlativos no Brasil. Boletim
Paranaense de Geografia, 16-17:153-197.

Bigazzi G., Hadler Neto J.C., Iunes P.J., Mello T.C.P.W.P., Navia L.M.S., Paulo S.R., Zuñiga A. 1995a. Employment of thin thorium films in fission track neutron dosimetry. Brazilian Journal of Physics, 25:246-251.

Bigazzi G., Hadler Neto J.C., Iunes, P.J.; Odone, M.; Paulo, S.R.; Zuñiga, A. 1995b. Absolute thermal neutron fluence determination by thin film of natural uranium. Nuclear Instruments and Methods A, 352:588-591.

Bigazzi G., Hadler Neto J.C., Iunes P.J., Khouri M.C., Navia L.M.S., Osório A.M.A., Paulo S.R., Zuñiga A. 1995c. Problems related to the employment of thin uranium films as neutron dosimeters. Radiatiation Measurements, 25:459-460.

Bigazzi G., Guedes S., Hadler Neto J.C., Iunes P.J., Odone M., Osório A.M.A, Paulo S.R., Zuñiga A. 1999. Potentialities and practical limitations of an absolute neutron dosimetry using thin films of natural uranium and thorium applied to the fission track method. Radiatiation Measurements, 31:651-656.

Bizzi L.A., Schobbenhaus C., Gonçalves J.H., Baars F.J., Delgado I.M.O., Abram M.B., Leão Neto R., Muniz de Matos G.M., Schneider Santos J.O. 2001. Mapas de Geologia, Tectônica e Recursos Minerais do Brasil: Sistema de Informações Geográficas - SIG. Brasília: CPRM, mapas geológicos escala 1:2.500.000, 4 CD-Rom.

Braun J. 2002. Quantifying the effect of recent relief changes on age-elevation relationships. Earth and Planetary Science Letters, 200:331-343.

Braun J. 2005. Quantitative constraints on the rate of landform evolution derived from low-temperature thermochronology. Reviews in Mineralogy and Geochemistry, 58:351-374.

Braun J., van der Beek P., Batt G. 2006. Quantitative Thermochronology: Numerical Methods for the Interpretation of Thermochronological Data. Cambridge University Press, $258 \mathrm{p}$.

Burbank D.W. \& Anderson R.S. 2001. Tectonic Geomorphology. Blackwell Publishing, 274 p.

Campanha G.A.C., Bistrichi C.A., Almeida M.A. 1987. Considerações sobre a organização litoestratigráfica e evolução tectônica da Faixa de Dobramentos Apiaí. In: SBG, Simpósio Sul-Brasileiro de Geologia, 3, Curitiba. Atas, 2:725-742.

Campos Neto M.C. 2000. Orogenic systems from southwestern Gondwana: an approach to Brasiliano - Pan African cycle and orogenic collage in southeastern Brasil. In: Cordani U., Milani E.J., Thomaz Filho A., Campos D.A. (ed.) Tectonic Evolution of South AmericaPlatform. Rio de Janeiro, $31^{\text {st }}$ Internacional Geological Congress, p. 335-365.

Chang H.K., Kowsmann R.O., Figueiredo A.M.F., Bender A.A. 1992. Tectonics and stratigraphy of the East Brazil Rift system: an overview. Tectonophysics, 213:97-138.

Cordani U.G., Sato, K., Teixeira W., Tassinari C.C.G., Basei M.A.S. 2000. Crustal Evolution of the South American platform. In: Cordani U., Milani E.J., Thomaz Filho A., Campos D.A. (ed.) Tectonic Evolution of South America Platform. Rio de Janeiro, $31^{\text {st }}$ Internacional Geological Congress, p. $19-40$.

Fernandes L.A. \& Coimbra A.M. 1996. A Bacia Bauru (Cretáceo Superior, Brasil). Anais da Academia Brasileira de Ciências, 68(2):195-205.

Fernandes L.A. \& Coimbra A.M. 2000. Revisão estratigráfica da 
parte oriental da Bacia Bauru (Neocretáceo). Revista Brasileira de Geociências, 30(4):717-728.

Ferreira F.J.F. 1982. Integração de dados aeromagnéticos e geológicos: configuração e evolução do Arco de Ponta Grossa. São Paulo, Dissertação de Mestrado, Instituto de Geociências, Universidade de São Paulo, 169 p.

Fiori A.P. 1992. O Sistema de Dobramento Apiaí, Estado do Paraná. Revista Brasileira de Geociências, 23:5-17.

Fitzgerald P.G., Sorkhabi R.B., Redfield T.F., Stump E. 1995. Uplift and denudation of the central Alaska Range: a case study in the use of apatite fission track thermochronology to determine absolute uplift parameters. Journal of Geophysical Research, 100:20,175-20,191.

Franco A.O.B. 2006. Termocronologia por Traços de Fissão em Apatitas na região do Arco de Ponta Grossa, entre os Alinhamentos de Guapiara e São Jerônimo-Curiúva. Universidade Estadual Paulista, Dissertação de Mestrado, 123 p.

Franco A.O.B., Hackspacher P.C., Godoy D.F., Ribeiro L.F.B., Guedes S. 2005. História térmica do Maciço Alcalino de Poços de Caldas (SP/MG) e adjacências através da análise de datação por traços de fissão em apatitas. Revista Brasileira de Geociências, 35:351-358.

Franco-Magalhães A.O.B. 2009. Exumação tectônica e evolução associada do relevo no Arco de Ponta Grossa, sul-sudeste do Brasil. Tese de Doutoramento, Universidade Estadual Paulista, $121 \mathrm{p}$.

Fulfaro V.J., Saad A.R., Santos M.V., Vianna R.B. 1982. Compartimentação e evolução tectônica da Bacia do Paraná. Revista Brasileira de Geociências, 12(4):590-611.

Gallagher K., Hawkesworth C.J., Mantovani M.S.M. 1995. Denudation, fission track analysis and the long-term evolution of passive margin topography: application to the southeast Brazilian margin. Journal of South American Earth Sciences, 8(1):65-77.

Gleadow A.J.W. \& Duddy I.R. 1981. A natural long term annealing experiment for apatite. Nuclear Tracks, 5:169-174.

Guedes S., Hadler Neto J.C., Iunes P.J., Tello C.A. 2004. Kinetic model for the relationship between confined fission-track length shortening and fission-track age reduction in minerals. Nuclear Instruments and Methods B, 217: 627-636.

Green P.F. 1988. The relationship between track shortening and fission track age reduction in apatite. Combined influence of inherent stability, annealing anisotropy, length bias and system calibration. Earth Planetary Science Letters. 89:335352.

Green P.F., Duddy I.R., Laslett G.M., Hegarty K.A., Gleadow A.J.W., Lovering J.F. 1989. Thermal annealing of fission tracks in apatite, 4. Quantitative modelling techniques and extension to geological timescales. Chemical Geology (Isotope Geoscience Section), 79:155-182.

Hackspacher P.C., Ribeiro L.F.B., Ribeiro M.C.S., Hadler Neto J.C., Tello C.A.S. 2003. A origem da Serra do Mar. Termocronologia por traços de fissão em apatitas. In: SBG, Simpósio Nacional de Estudos Tectônicos, 3, Armação de Búzios, Boletim de Resumos, p. 384-385.

Hackspacher P.C., Ribeiro L.F.B., Ribeiro M.C.S., Fetter A.H., Hadler Neto J.C., Tello C.A.S., Dantas E.L. 2004. Consolidation and Break-up of the South American Platform in Southeastern Brazil: Tectonothermal and Denudation Histories. Gondwana Research, 7(1):91-101.
Hackspacher P.C., Godoy D.F., Ribeiro L.F.B., Hadler Neto J.C., Franco A.O.B. 2007. Modelagem térmica e geomorfologia da borda sul do Cráton do São Francisco: termocronologia por traços de fissão em apatita. Revista Brasileira de Geociências, 37(4-suplemento):76-86.

Hasui Y., Carneiro C.D.R., Coimbra A.M. 1975. The Ribeira Folded Belt. Revista Brasileira de Geociências, 5(4):257- 262.

House M.A., Wernicke B.P., Farley K.A. 1998. Dating topography of the Sierra Nevada, California, using apatite (U-Th)/ He ages. Nature, 396:66-69.

Iunes P.J., Hadler Neto J.C., Bigazzi G., Tello C.A.S., Guedes S., Paulo S.R. 2002. Durango apatite fission-track dating using length-based age corrections and neutron fluence measurements by natural thorium thin films and U-doped glasses calibrated through natural uranium thin films. Chemical Geology, 187: 201-211.

King L.C. 1956. A geomorfologia do Brasil Oriental. Revista Brasileira de Geografia, 18(2):147-165.

Maack R. 1948. Notas preliminares sobre clima, solos e vegetação do Estado do Paraná. Arquivos de Biologia e Tecnologia (Curitiba), 2:102-200.

Machado Jr. D.L. 2000. Condicionamento Estrutural e Contexto Tectônico do “Alinhamento de Guapiara”. São Paulo, Tese de Doutoramento, Instituto de Geociências, Universidade de São Paulo, 143 p.

Melo M.S. de. 1990. A Formação Pariquera-Açu e depósitos relacionados: sedimentação, tectônica e geomorfogênese. São Paulo, Dissertação de Mestrado, Universidade de São Paulo, 211 p.

Melo M.S., Fernandes L.A., Coimbra A.M., Ramos R.G.N. 1989. O Gráben (Terciário?) de Sete Barras, Vale do Ribeira de Iguape, SP. Revista Brasileira de Geociências, 19:260262.

Melo M.S., Giannini P.C.F., Pessenda L.C.R. 2000. Gênese e evolução da Lagoa Dourada, Ponta Grossa, PR. Revista do Instituto Geológico, 21(1/2):17-31.

Melo M.S., Riccomini C., Hasui Y., Almeida F.F.M., Coimbra A.M. 1985. Geologia e evolução do sistema de bacias tafrogênicas continentais do sudeste do Brasil. Revista Brasileira de Geociências, 15(3):193-201.

Milani E.J. 1997. Evolução tectono - estratigráfica da Bacia do Paraná e seu relacionamento com a geodinâmica fanerozóica do Gondwana Sul - Ocidental. Tese de Doutoramento, Instituto de Geociências, Universidade Federal do Rio Grande do Sul, 255 p., 2 vol.

Milani E.J. \& Ramos V. 1998. Orogenias Pós-Paleozóicas no Domínio Sul-Ocidental do Gondwana e os Ciclos de Subsidência da Bacia do Paraná. Revista Brasileira de Geociências, 28(4):473-484.

Minerais do Paraná S.A. (MINEROPAR) 2003. Mapa Geológico do Estado do Paraná. Escala 1:250.000.

Modica J.C. \& Brush E. 2004. Postrift sequence stratigraphy, paleogeography, and fill history of the deep-water

Santos Basin, offshore southeast Brazil. AAPG Bulletin, 88(7):923-945.

Naeser C.W. \& Forbes R.B. 1976. Variation of fission track ages with depth in two deep drill holes. EOS

(American Geophysical Union Transactions), 57(4):353.

Pereira M.J. \& Feijó F.J. 1994. Bacia de Santos. Boletim de Geociências da Petrobrás, 8(1):219-234. 
Piccirillo E.M. \& Melfi A.J. (eds.) 1988. The Mesozoic Flood Volcamism of the Paraná Basin: Petrogenetic and Geophysiscal Aspects. São Paulo, Instituto Astronômico e Geofísico, Universidade de São Paulo, 600 p.

Piccirillo E.M., Melfi A.J., Comin-Chiaramonti P., Bellieni G., Ernesto M., Marques L.S.; Nardy A.J.R., Pacca I.G., Roisenberg A., Stolfa D. 1988. Continental Flood Volcanism from the Paraná Basin (Brazil). In: McDougall J.D. (ed.) Continental Flood Basalts. Dordrecht, p. 195-238.

Portela Filho C.V. \& Ferreira F.J.F. 2003. Estimativas das taxas de extensão crustal da região central do Arco de Ponta Grossa (Bacia do Paraná) com base em modelagens aeromagnéticas. In: Congresso Internacional da Sociedade Brasileira de Geofísica, 8, Rio de Janeiro, RJ, Resumos Expandidos, CD-ROM.

Reiners P.W. \& Ehlers T.A. (eds.) 2005. Low-Temperature Thermochronology: Techniques, Interpretations, Applications. Reviews in Mineralogy and Geochemistry, 58. Chantilly, V.A.: Mineralogical Society of America, Geochemistry Society, $622 \mathrm{p}$.

Renne P.R., Ernesto M., Pacca I.I.G., Coe R.S., Glen J.M., Prévot M., Perrin M. 1992. The age of Paraná flood volcanism, rifting of Gondwanaland, and the Jurassic -Cretaceous boundary. Science, 258:975-979.

Renne P.R., Deckart K., Ernesto M., Féraud G., Piccirillo E.M. 1996. Age of the Ponta Grossa dike swarm (Brazil), and implications to Paraná flood volcanism. Earth and Planetary Science Letters, 144:199-211.

Riccomini C. 1989. O Rift Continental do Sudeste do Brasil. Instituto de Geociências. São Paulo, Tese de Doutoramento, Universidade de São Paulo, 256 p.

Riccomini C. 1995. Tectonismo gerador e deformador dos depósitos sedimentares pós-gondwanicos da porção centrooriental do estado de São Paulo e áreas vizinhas. São Paulo, Tese de Livre Docência, Instituto de Geociências, Universidade de São Paulo, 100 p.

Riccomini C. 1997. Arcabouço Estrutural e Aspectos do Tectonismo Gerador e Deformador da Bacia Bauru no Estado de São Paulo. Revista Brasileira de Geociências, 27(2):153-162.

Riccomini C., Sant'Anna L.G., Ferrari A.L. 2004. Evolução Geológica do Rift Continental do Sudeste do Brasil. In: Mantesso Neto V., Bartorelli A., Carneiro C.D.R., Neves B.B.B. (orgs.) Geologia do Continente Sul-Americano: Evolução da Obra de Fernando Flávio Marques de Almeida. São Paulo, Editora Beca, p. 383-405.

Riccomini C., Velázquez V.F., Gomes C.B. 2005. Tectonic controls of the mesozoic and cenozoic alkaline magmatism in central-southeastern Brazilian Platform. In: Comin-Chiaramonti P. \& Gomes C.B. (eds.) Mesozoic to Cenozoic alkaline magmatism in the Brazilian Platform. São Paulo: Edusp/Fapesp, p. 31-55.
Römer W. 2008. Accordant summit heights, summit levels and the origin of the "upper denudation level" in the Serra do Mar (SE-Brazil, São Paulo): a study of hillslope forms and processes. Geomorphology, 100:312-327.

Salamuni E. 1998. Tectônica da Bacia Sedimentar de Curitiba $(P R)$. Rio Claro, Tese de Doutoramento, Universidade Estadual Paulista, 214 p.

Salamuni E., Ebert H.D., Hasui Y. 2003. Morfotectônica da Bacia Sedimentar de Curitiba. Revista Brasileira de Geociências, 34(4):469-478.

Salamuni E., Ebert H.D., Borges M.S., Hasui Y., Costa J.B.S., Salamuni R. 2004. Tectonics and sedimentation in the $\mathrm{Cu}-$ ritiba Basin, south of Brazil. Journal of South American Earth Sciences, 15:901-910.

Souza L.A.P., Tessler M.G., Galli V.L. 1996. O Gráben da Cananéia. Revista Brasileira de Geociências, 26:139-150.

Tello C.A.S. 1998. Estudo de annealing de traços de fissão em apatitas, tanto em seções basais quanto em seções sem orientação preferencial, análise dos comprimentos dos traços de fissão. Tese de Doutoramento, Instituto de Física Gleb Wataghin, Universidade de Campinas, $111 \mathrm{p}$.

Tello C.A.S., Hackspacher P.C., Hadler Neto J.C., Iunes P.J., Guedes S., Paulo S.R., Ribeiro L.F.B. 2003. Recognition of Cretaceous, Paleocene and Neogene Tectonic Reactivation, through Apatite Fission-Track Analysis, in Precambrian areas of the Southeast Brazil: Association with the South Atlantic Ocean Opening. Journal of South American Earth Science, 15:137-142.

Vignol-Lelarge M.L.M., Soliani Jr. E., Poupeau G. 1994. Datação pelos traços de fissão do Domínio Meridional da Serra do Mar (Arco de Ponta Grossa - Brasil). In: SBG, Congresso Brasileiro de Geologia, Balneário Camboriú, 38, Anais, 1:379-380.

Wagner G. \& Van Den Haute P. 1992. Fission Track Dating. Kluwer Academic Publishers, 283 p.

Zalán P.V. \& Oliveira J.A.B. 2005. Origem e evolução estrutural do Sistema de Riftes Cenozóicos do Sudeste do Brasil. Boletim de Geociências da Petrobrás, 13(2):269-300.

Zalán P.V., Wolf S., Conceição J.C.J., Astolfi M.A.M., Vieira I.S., Appi V.T., Zanotto O.A. 1987. Tectônica e Sedimentação da Bacia do Paraná. In: Simpósio Sul Brasileiro de Geologia, Curitiba, Atas, 3:441-447.

Zalán P.V., Wolff S., Conceição J.C., Marques A., Astolfi M.A. M., Vieira I.S., Appi V.T. 1990. Bacia do Paraná. In: Raja Gabaglia G.P. \& Milani E.J. (coords.) Origem e evolução de Bacias Sedimentares. Rio de Janeiro, PETROBRAS, p. 135-164.

Manuscrito ID 14700

Submetido 02 de julho de 2009 Aceito em 01 de junho de 2010 